\title{
Relationship of Body Mass Index to Genu Osteoarthritis in Orthopedic Polyclinic Tarakan Hospital Jakarta in August-October 2019
}

\author{
Agus Yudawijaya ${ }^{1}$, Tranggono Yudo Utomo ${ }^{1,2}$, Vanessa Destiana ${ }^{1}$ \\ ${ }^{1}$ Faculty of Medicine, Universitas Kristen Indonesia, Jakarta \\ ${ }^{2}$ RSUD Dr. Chasbullah Abdulmajid, Indonesia, Bekasi
}

Corresponding Author: Agus Yudawijaya

\begin{abstract}
Osteoarthritis is a chronic and degenerative disease characterized by pain and damage to joint cartilage, which often causes pain and limited movement in the elderly population to disrupt daily activities and cause severe socio-economic impacts. The risk factor is more than 50 years, female gender, obesity, history of knee trauma, and anatomical abnormalities. This study was conducted to determine the relationship between body mass index to the degree of genu osteoarthritis. The design of this study was observational analytic with a cross-sectional study approach, using consecutive sampling. The tools used are medical record paper, weight scales, staturmeter, $\mathrm{X}$ photo articulation genu. Parameters examined were gender, age, weight (BB), height (TB), grade osteoarthritis (OA) genu Kellgren-Lawrence. It is conducted at Tarakan Hospital, Jakarta. The results showed $67,5 \%$ of respondents were female, $67,5 \%$ of respondents with OA genu aged $>50$ years, $67,5 \%$ of respondents with $\mathrm{BMI} \geq 23,17,5 \%$ OA genu with grade Kellgren-Lawrence 1, 22,5\% OA genu with grade Kellgren-Lawrence 2, 30\% OA genu with grade Kellgren-Lawrence 3 and 30\% OA genu with Kellgren-Lawrence 4 . Results of the chi-square test have a relationship between body mass index ( $\mathrm{p}=$ 0.042) on the degree of osteoarthritis genu in Tarakan Hospital, Jakarta. It was concluded that there was a relationship between body mass index to the degree of osteoarthritis genu in Tarakan Hospital, Jakarta.
\end{abstract}

Keywords: Osteoarthritis, Body Mass Index, Grade OA Genu Kellgren-Lawrence.

\section{INTRODUCTION}

Osteoarthritis is a chronic and degenerative joint disease. It is characterized by pain and joint cartilage damage that causes limited movement in the elderly population to interfere with daily activities ${ }^{[1]}$. The World Health Organization (WHO) reported that the prevalence of osteoarthritis in the world in 2004 reached 151.4 million people and 27.4 million people were in Southeast Asia ${ }^{[2]}$. Research in the UK shows that $10 \%$ to $13 \%$ of men and women aged $>50$ years have symptoms of genu osteoarthritis. In Indonesia, genu osteoarthritis is relatively high, reaching $15.5 \%$ in men and $12.7 \%$ in women ${ }^{[3]}$. Risk factors for osteoarthritis genu include age more than 50 years, female gender, genetics, smoking habits, obesity, osteoporosis, diabetes mellitus, hypertension, hyperuricemia, hysterectomy, meniscectomy, history of knee trauma and anatomical abnormalities. Kun Salimah, in his research on the relationship between risk factors for Body Mass Index and the incidence of knee osteoarthritis in outpatients with poly rheumatism at RS. Dr Kariadi Semarang, in March-June 2005 that a person with a Body Mass Index> 22 (overweight) has a risk of developing knee osteoarthritis 2,083 times greater than someone with a Body Mass Index <22 ${ }^{[3]}$. 
Overweight was defined as body weight that exceeds average body weight, with a body mass index (BMI) status of 23 in adults. Obesity is an increase in body weight beyond the limits of physical and skeletal needs, resulting from excessive accumulation of body fat. Overweight and obesity are conditions where the ratio of body weight and height exceeds the universally established standards but are two different things. Obesity occurs when the size and number of fat cells increase in the body. Genetic factors play a significant role in obesity ${ }^{[4]}$. According to Soros, obese osteoarthritis patients often complain of pain in the knee joint compared to nonobese patients. The higher the rate of weight gains more than average, the worsening of osteoarthritis. In this case, overweight and obese are classified according to body mass index. Because obesity is one of the risk factors for osteoarthritis, this study will look for the relationship of excess body weight, assessed based on body mass index, to the degree of osteoarthritis genu KellgrenLawrence classification ${ }^{[5]}$. The problem that was answered in this study was "Is there a relationship between body mass index (BMI) and the degree of osteoarthritis genu at Tarakan Hospital Jakarta?" with the aim of the study, namely to determine the relationship between body mass index (BMI) and the degree of osteoarthritis genu at Tarakan Hospital, Jakarta.

\section{LITERATURE REVIEW}

Osteoarthritis - Osteoarthritis is the most common rheumatic disease compared to cases of other rheumatic diseases. The prevalence and incidence of osteoarthritis increased by 3 -fold in women compared to men, according to O'connor's study ${ }^{[6]}$. In Indonesia, the prevalence of joint disease diagnosed by health workers has increased with age. The highest prevalence occurs at over 50 years of age ${ }^{[7]}$. Some of the factors that cause osteoarthritis are increasing age ${ }^{[8]}$, obesity ${ }^{[9]}$, female gender ${ }^{[10]}$, history of trauma ${ }^{[11]}$, genetic factors ${ }^{[8]}$, and work with heavy loads ${ }^{[8]}$.
Clinical Symptoms - The symptoms caused by osteoarthritis are the emergence of joint pain, especially joints used to move or bear loads. The pain will be reduced when you rest, and stiffness of the joints will usually be felt, especially in the morning. In addition, there are joint deformities. The presence of crepitus in painful joints and the presence of ROM (range of movement) disturbances affect gait and daily activities. Total Knee Replacement is indicated for patients who experience severe pain and functional disabilities due to joint surface damage due to arthritis ${ }^{[5]}$.

Pathophysiology - OA is caused by changes in the biomechanical and biochemical cartilage that occur due to several causes, including age, stress, or overuse of joints, anatomic defects, obesity, genetics, and humoral, where there will be an imbalance between bone degradation and synthesis prone, causing the release of degradation enzymes and collagen release, resulting in damage to joint cartilage and synovium. Osteophyte formation will later also occur as a repair process to reshape the joint to be seen as a progressive joint disorder ${ }^{[9]}$. Osteoarthritis arises from disorders of cartilage metabolism and proteoglycan damage with various causes, one of which is a mechanical and chemical injury to the synovial joints. When a joint is injured, there will be chondrocyte multiplication and the production of a new matrix. Chondrocytes will synthesize DNA and collagen, and proteoglycans. However, there is an imbalance between the synthesis and the degradation of collagen and protein. An increase in the products of degradation of the cartilage matrix will collect in the joints, causing inflammation ${ }^{[10]}$.

In the cartilage of patients with OA, there was also an increase in fibrinogen activity and decreased fibrinolytic activity. As a result, there is an accumulation of thrombus and lipids in the subchondral blood vessels, resulting in tissue ischemia and necrosis. This inflammatory process will result in the release of chemical 
mediators causing pain ${ }^{[11]}$. Obesity is one of the biomechanical factors that cause injury. The impact caused by obesity is known as "wear and tear" only. Obesity is associated with chronic low-grade inflammation of the system. With obesity, there is an increase in the mass of fat tissue or adipose tissue, which is a source of local and systemic inflammation. Some diseases are involved in increased adipose, such as type 2 diabetes, cardiovascular disease, cancer. Adipose tissue-related proinflammatory cytokines such as interleukin 1 (IL-1), IL-6, and TNF- $\alpha$ affect cartilage. Adipose-derived cytokines are believed to play an essential role in several diseases associated with metabolic syndrome ${ }^{[12]}$.

Complications - Spontaneous osteonecrosis of the knee joint, bursitis, microcrystalline arthropathy can be complications ${ }^{[5]}$.

Classification of Degree of Osteoarthritis Genu Kellgren-Lawrence Kellgren-Lawrence classification for osteoarthritis based on radiographs as follows: Grade 0: Normal, no abnormal radiological features, Grade 1: Doubtful, visible small osteophytes, Grade 2: Minimal, visible osteophytes, joint fissures normal, Grade 3: Moderate, clear osteophytes, joint space narrowing, Grade 4: Severe, severe joint space narrowing and the presence of sclerosis ${ }^{13]}$.

Body Mass Index - Body Mass Index (BMI) is a simple way to monitor nutritional status compared to underweight and overweight. Being underweight increases the risk of infectious diseases while being overweight increases the risk of degenerative diseases ${ }^{[14]}$. To monitor the Body Mass Index, a weight scale $(\mathrm{kg})$ and a height meter $(\mathrm{cm})$ is used. To find out this BMI value, it can be calculated by the following formula:

$$
\text { BMI }=\frac{\text { Weight }(\text { Kg })}{\text { Height }(\mathbf{m}) \text { X Height }(\mathbf{m})}
$$

The BMI threshold used for Indonesia is taken from the criteria for weight and obesity in the Asia Pacific region as follows:

Table 1. Body Mass Index (BMI) According to Asia Pacific Criteria [12; 14]

\begin{tabular}{|l|l|}
\hline Category & BMI \\
\hline Less weight & $<18,5$ \\
\hline Normal range & $18,5-22,9$ \\
\hline More weight & $\geq 23,0$ \\
\hline Preobesity & $23,0-24,9$ \\
\hline Obesity I & $25,0-29,9$ \\
\hline Obesity II & $>30,0$ \\
\hline
\end{tabular}

Knee Joint - The joint (articulatio) is a connection between two or more bones connected through connective tissue on the outside and the inside. The knee joint is a joint in the inferior limb that connects the upper leg (thigh/femur) to the lower leg (tibia). The function of this joint is to perform flexion, extension, and slight rotation of the lower leg ${ }^{[15]}$. The articulatio genus (knee joint) is the largest and most complex joint in the entire body. This joint consists of two condylar joints between the medial and lateral condyles with the condyles of the tibiae and a saddle joint between the patella and the facies patellar femoris over the tibial condyles ${ }^{[16 ; 17]}$.

The patella, a type of sesamoid bone, is located in the inferior segment of the tendon quadriceps femoris on the anteroinferior surface. The upper, lateral, and medial margins are the attachment sites for various parts of them. Patella is prevented from displacing laterally during contraction m. quadriceps femoris by lower horizontal fibres $\mathrm{m}$ vastus medialis, and by the size of the lateral condyles of the femoris, the stability of the knee joint depends on the tone of the strong muscles acting on the joint and the strength of the ligaments ${ }^{[16 ; 17 ; 18]}$. 


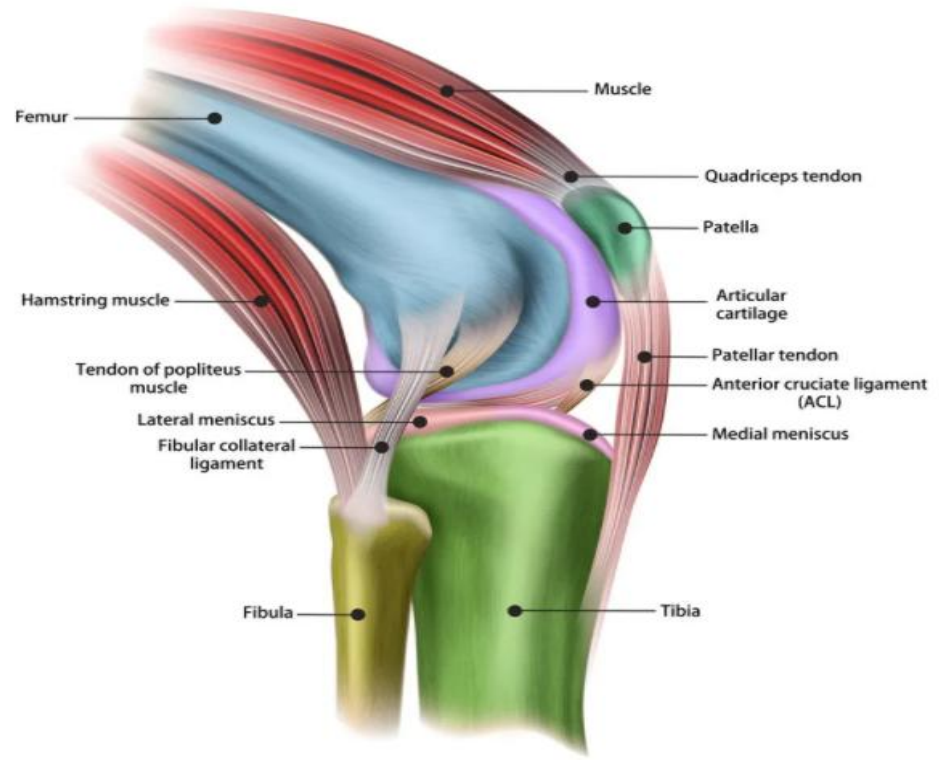

Figure 1. Knee Joint Anatomy [Source: https://www.joionline.net/trending/content/knee-anatomy]

Ligaments in the Knee Joint - The ligaments in the knee joint are grouped into extracapsular ligaments and intracapsular ligaments. The extracapsular ligament consists of five ligaments: the patellae ligament, the collateral fibulare ligament, the tibiae collateral ligament, and the popliteus oblique ligament, and the genu transverse ligament ${ }^{[19]}$. Meanwhile, the intracapsular ligament consists of only two cruciate ligaments, namely the anterior cruciate ligament and the posterior cruciate ligament, according to its attachment to the os. The cruciate ligaments are two powerful intracapsular ligaments. These two ligaments cross each other in the joint cavity. This ligament is crucial because it is the primary binding between the os femur with os tibiae. Several ligament parts include ligament patellae, ligament collateral fibulare, ligament collateral tibiae, and ligament popliteal oblique, transverse ligament genus, ligament anterior cruciate, and ligament cruciate posterior ${ }^{[19 ; 20]}$.

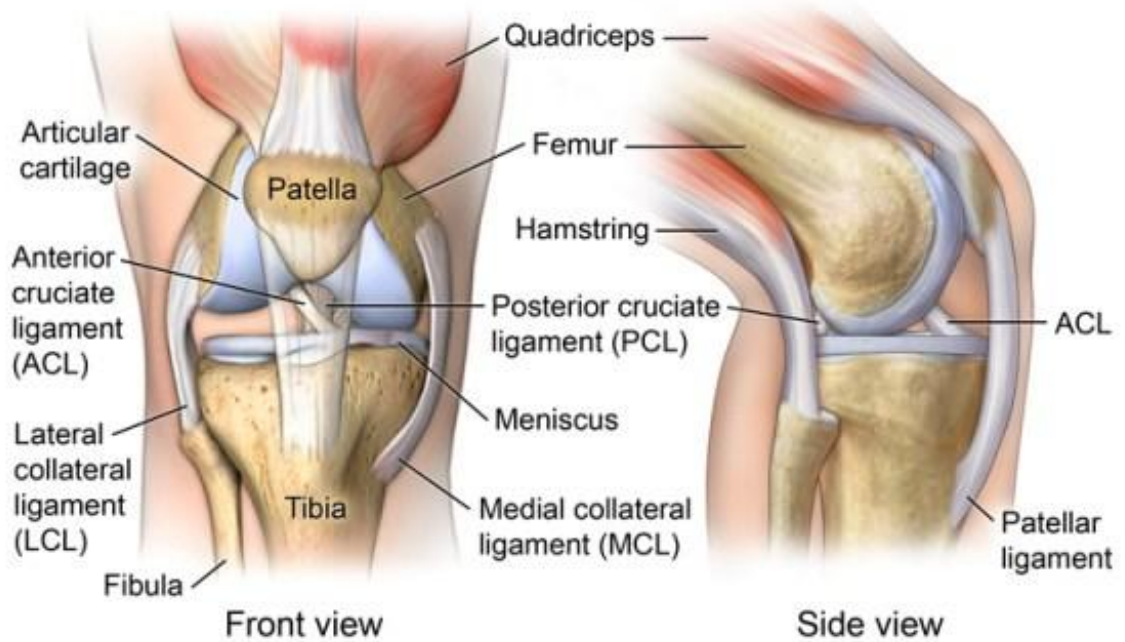

Figure 2. Ligaments of the Knee Joint [https://flexfreeclinic.com/infokesehatan/detail/69?title=cedera-lutut-bagian-i]

Cartilage Semilunaris (Meniscus) Cartilago semilunaris, often referred to as meniscus, is a fibrocartilage lamella in the shape of the letter $C$. This meniscus in cross-section will appear triangular. The peripheral borders are thick and convex, 
attached to the bursa. In contrast, the inner boundary is concave and forms a free edge. The upper surface of the meniscus is concave and is in direct contact with the condyles of the femoris. The function of the meniscus is to deepen the articular fascias of the tibial condyle to receive the concave condyle of the femoris. According to its location, the cartilage semilunaris can be divided into two. Namely, cartilage semilunaris medialis and cartilage semilunaris lateralis ${ }^{[20]}$.

Articular capsule - The articular capsule is located on the posterior surface of the tendon quadriceps femoris. The articular capsule covers the patella from the front toward the anterior surface of the femur over the articular tuberosity. Then the capsule continues as a loose membrane separated by thick fatty tissue from the patellae ligament. From the centre of the retinacula patellae, the capsule articular goes to the upper edges of the two menisci, then downwards and attaches to the anterior cruciate ligament. Furthermore, this particular capsule covers the two cruciate ligaments of the knee joint as a sheet and crosses the posterior edge of the posterior cruciate ligament. The capsule articular forms two protrusions, a synovial fold, and the plica alarms collected at the bottom from the medial and lateral edges of the articular fascias. All of these form synovial villi $^{[1]}$.

The patellar synovial extends at the back, leading to the sagittal plane to the joint cavity and is attached to the very bottom of the edge of the intercondyloide fossa femoris. This plica is a wide sagittal fold on the synovial membrane. This fold divides the joint cavity into two parts, which correspond to the two condyles femoris and tibiae pairs. The fold of the joint capsule on the side runs close to the cartilage edge so that the epicondyle region remains free. The joint capsule then covers the cartilage surface, but the cartilage does not cover the anterior surface of the femur. In the tibia, the joint attaches capsule around the margo infra glenoidalis, slightly below the surface of the cartilage, then travels to the underside of the edge of each meniscus ${ }^{[21]}$.

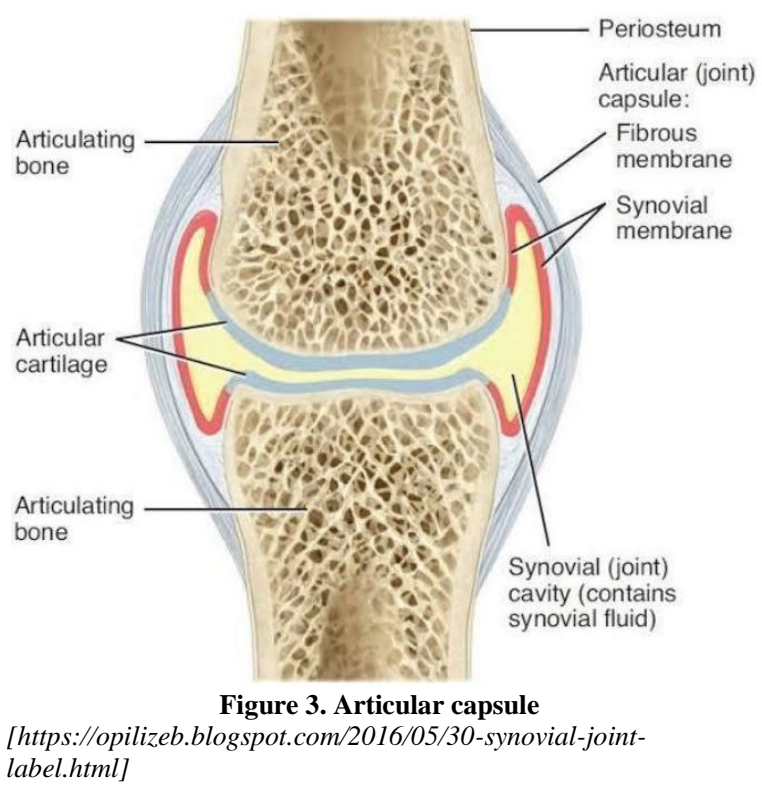

The knee joint - The knee joint is a pocket-like tube located at the bottom and back on the lateral side in front and below the origami popliteus tendon. This bursa opens toward the joint employing a narrow opening above the lateral meniscus and popliteus tendon. Many bursae are associated with the knee joint. The four bursae are at the front, and the six bursae are behind the joint. This bursa is where the friction occurs between the bone and skin, bone to muscle, or bone to tendon [21]. According to their place, there are two types of the bursa in the knee joint, namely the anterior bursa and the posterior bursa. The anterior bursa is divided into four types: the suprapatellar bursa, the prepatellar bursa, the superficial infrapatellar exchange, and the deep infrapatellar exchange. Meanwhile, the posterior bursa is divided into two types: the sub-popliteus and the $\mathrm{m}$ bursa recess semimembranosus ${ }^{[21]}$.

Blood supply and innervation to the knee joint - The blood supply to the knee joint comes from anastomose of the blood vessels around this joint. The knee joint receives blood from the descending genicular femoral artery, the genicular branches of the popliteal artery, the descending branch of the femoral 
circumflex artery, and the ascending branch of the anterior tibial artery. The venous flow in the knee joint follows the passage of the artery to enter the femoral vein then. The innervation of the knee joint is through the nerves branches that supply the muscles around the knee joint. The knee joint is innervated by various nerves, namely the femoral nerve, obturator nerve, common peroneus nerve, and tibial nerve ${ }^{[21]}$.

\section{RESEARCH METHOD}

The design of this study was an observational analytic study with a crosssectional study approach to determine the relationship between variables which was carried out by data analysis. Cross-sectional is a study in which the measurement of the variables is carried out only once (simultaneously). In this case, to determine the relationship between BMI and the degree of osteoarthritis genu KellgrenLawrence classification using SPSS 22.0.
The research was carried out at the Orthopedic Polyclinic of Tarakan Hospital Jakarta, and data collection was carried out in August-October 2019. The population in this study were patients diagnosed with osteoarthritis genu and came to the orthopaedic polyclinic RSUD Tarakan Jakarta in August-October 2019. The sampling technique in this study is total sampling. Total sampling is a total sampling technique because the population is less than 100 . Where 40 respondents were found in Tarakan Hospital Jakarta, the data collection method will be carried out to use primary data obtained through interviews and BMI data obtained by direct measurement of patients at Tarakan Hospital Jakarta August-October 2019 period. The parameters examined are body mass index (BMI) and the degree of osteoarthritis genu using radiological photos.

Table 2. Operational Definition

\begin{tabular}{|c|c|c|c|c|}
\hline Variable & Operational Definition & Measuring instrument & Measuring Results & $\begin{array}{l}\text { Measuring } \\
\text { Scale }\end{array}$ \\
\hline $\begin{array}{l}\text { Body Mass Index } \\
\text { (BMI Criteria for the } \\
\text { Asia Pacific) }\end{array}$ & $\begin{array}{l}\text { The nutritional status of } \\
\text { workers at the time of the } \\
\text { study was calculated using } \\
\text { the formula BW (kg) / TB } \\
\text { (m) } 2\end{array}$ & $\begin{array}{l}\text { Scale }(\mathrm{kg}) \text { and Microtoise } \\
(\mathrm{cm})\end{array}$ & $\begin{array}{l}\text { Underweight: }<18.5 \\
\text { Normal Range: } 18.5-22.9 \\
\text { Overweight (overweight): } \geq 23.0 \\
\text { Preobesity: } 23.0-24.9 \\
\text { Obesity I: } 25.0-29.9 \\
\text { Obesity II: }>30.0\end{array}$ & $\begin{array}{l}\text { Ordinal } \\
\text { categorical }\end{array}$ \\
\hline & $\begin{array}{l}\text { The degree of osteoarthritis } \\
\text { according to the Kellgren- } \\
\text { Lawrence classification }\end{array}$ & Genu radiology photo & $\begin{array}{l}\text { Grade 0: Normal, no radiological } \\
\text { abnormalities } \\
\text { Grade 1: Dubious, appear to be } \\
\text { small osteophytes. } \\
\text { Grade 2: Minimal, visible } \\
\text { osteophytes, average joint gap. } \\
\text { Grade 3: Moderate, clear } \\
\text { osteophytes, joint } \\
\text { narrowing. } \\
\text { Grade 4: Severe, severe joint } \\
\text { space narrowing and sclerosis. }\end{array}$ & $\begin{array}{l}\text { Ordinal } \\
\text { categorical }\end{array}$ \\
\hline
\end{tabular}

After the data collection process is complete, data processing and analysis will be carried out. The data obtained will be processed by statistical techniques using the statistical product and service solution (SPSS) program. The data analysis was carried out in stages, consisting of univariate analysis and bivariate analysis. The univariate analysis aims to explain or describe each research variable which will be presented in tabular form. Then proceed with the bivariate analysis to find the relationship between BMI and osteoarthritis genu August-October 2019 period.

\section{RESULT AND DISCUSSION}

The research was conducted at the orthopaedic surgery polyclinic of Tarakan Hospital Jakarta. This study was conducted every day starting from August to October, where the respondents were patients who came to the polyclinic and were diagnosed with genu osteoarthritis. The researchers provided informed consent and collected 
data. This activity is carried out once a week in August - October 2019 to meet the total sample studied according to the criteria, namely 40 people.

Table 3. Gender Distribution of Respondents at RSUD Tarakan Jakarta.

\begin{tabular}{|l|l|l|}
\hline Characteristics of Respondents & $\mathbf{n}$ & $\begin{array}{l}\text { Percentage Frequency } \\
(\boldsymbol{\%})\end{array}$ \\
\hline Gender & & \\
\hline Man & 13 & 32,5 \\
\hline Women & 27 & 67,5 \\
\hline Total & 40 & 100,0 \\
\hline
\end{tabular}

Based on table 3, it is found that the total numbers of female and male respondents are 40 people. The most frequent gender was female, which were 27 people with a percentage of $67.5 \%$.

Table 4. Age Distribution of Respondents at Tarakan Hospital, Jakarta.

\begin{tabular}{|l|l|l|}
\hline Characteristics of Respondents & $\mathbf{n}$ & $\begin{array}{l}\text { Percentage Frequency } \\
(\boldsymbol{\%})\end{array}$ \\
\hline Gender & & \\
\hline$\leq 50$ years & 13 & 32,5 \\
\hline$>50$ Years & 27 & 67,5 \\
\hline Total & 40 & 100,0 \\
\hline
\end{tabular}

Based on table 4, it is found that the total respondents aged $\leq 50$ years and $>50$ years are 40 people. The highest frequency at age was $>50$ years, as many as 27 people with a percentage of $67.5 \%$.

Based on table 5., it is found that the total respondents BMI $<23$ and $\geq 23$ are 40 people. The highest frequency for BMI is in the category $\geq 23$, namely 27 people with a percentage of $67.5 \%$

Table 5. Distribution of Body Mass Index of Respondents at Tarakan Hospital, Jakarta.

\begin{tabular}{|l|l|l|l} 
Characteristics of Respondents & $\mathbf{n}$ & Percentage Frequency \\
\hline
\end{tabular}

\begin{tabular}{|l|l|l|} 
& & $\mathbf{( \% )}$ \\
\hline Gender & & \\
\hline BMI $<23$ & 13 & 32,5 \\
\hline BMI $\geq 23$ & 27 & 67,5 \\
\hline Total & 40 & 100,0 \\
\hline
\end{tabular}

Table 6. Distribution of Osteoarthritis Grade according to Kellgren-Lawrence Respondents of Tarakan Hospital, Jakarta.

\begin{tabular}{|l|l|l|}
\hline Characteristics of Respondents & $\mathbf{n}$ & $\begin{array}{l}\text { Percentage Frequency } \\
(\mathbf{\%})\end{array}$ \\
\hline Gender & & \\
\hline Grade 1 & 7 & 17,5 \\
\hline Grade 2 & 9 & 22,5 \\
Grade 3 & 12 & 30,0 \\
Grade 4 & 12 & 30,0 \\
\hline Total & 40 & 100,0 \\
\hline
\end{tabular}

Based on table 6 , it is found that the total number of respondents of Grade Osteoarthritis is 40 people. The highest frequency was in grade 3 and grade 4, namely 12 people, each with a percentage of $30.0 \%$.

Bivariate Analysis - The bivariate analysis connects variables to determine whether there is a relationship between the two variables. In this study, researchers examined the variables body mass index (BMI) and age against the degree or grade of osteoarthritis. Genu can be seen in table 7.

Table 7. Crosstabulation of BMI Variables and Degree of Genu Osteoarthritis Relationship between body mass index and the degree of genu osteoarthritis at tarakan hospital, jakarta in august - october 2019

\begin{tabular}{|c|c|c|c|c|c|c|}
\hline \multicolumn{2}{|c|}{ Individual Factors } & \multicolumn{4}{|c|}{ Kellgren-Lawrence Grade } & \multirow[t]{2}{*}{ P-Value } \\
\hline & & Grade 1 & Grade 2 & Grade 3 & Grade 4 & \\
\hline \multirow[t]{4}{*}{ BMI } & \multirow[t]{2}{*}{$<23$} & 5 & 3 & 4 & 1 & \multirow[t]{4}{*}{0,045} \\
\hline & & $71,4 \%$ & $33,3 \%$ & $33,3 \%$ & $8,3 \%$ & \\
\hline & \multirow[t]{2}{*}{$\geq 23$} & 2 & 6 & 8 & 11 & \\
\hline & & $28,6 \%$ & $66,7 \%$ & $66,7 \%$ & $91,7 \%$ & \\
\hline
\end{tabular}

The table shows that in the category BMI <23, 5 people have grade 1,3 people have grade 2,4 people have grade 3 , and 1 person has grade 4 . The BMI category 23 shows two people have grade 1,6 people have grade 2,8 people had grade 3 , and 11 people had grade 4. After using the SPSS 22.0 application, crosstabs were carried out with the chi-square test, where the value of the expected count was $\mathrm{p}=0.042<\alpha(0.05)$ so that there was a relationship between indexes body mass with genu degree of osteoarthritis.

It means that there is a relationship between body mass index and the degree of osteoarthritis genu. These results are in line with research conducted that patients with a BMI 23 have a higher degree of knee osteoarthritis, which is $88.9 \%^{[22 ; 23]}$. People who are severely obese can suffer from genu osteoarthritis 2.51 times compared to people who are not severely obese ${ }^{[24]}$. 
A study conducted by M Reijman, HAP Pols, et al. on "Body Mass Index Associated with Onset and Progressivity but Not Hip" showed that a high BMI (> 27.5 $\mathrm{kg} / \mathrm{m} 2)$ was significantly associated with the development of radiological features of knee osteoarthritis ${ }^{[25]}$. It explains that radiological photos can assess the grade of osteoarthritis genu, especially if one is overweight or obese. The researchers took several photos as evidence and can be seen on the appendix page.

Through theory, it is known that osteoarthritis is a first-order joint disease that causes pain and inability to walk properly and generally attacks the weightbearing joints, especially the knee joints ${ }^{[26 ;}$ 27]. Likewise, if someone is overweight, it can interfere with the knee joint and not rule out osteoarthritis genu. It is in line with the theory that obesity is a multifactorial disease that results in excessive fat deposits resulting in health problems ${ }^{[28]}$.

Strengths and Limitations of Research - The strength of this study is that a similar study has never been conducted at the Tarakan Hospital Jakarta, and the respondents themselves gave positive responses during the research. The limitation of the research itself is time, and this is because the process of issuing a letter of ethics is too long and delayed, then the time limit is when the respondent's data collection is waiting for the results of radiological photos and the researcher himself has to compensate for lecture hours and research hours. The drawback of this study is that in several letters of knee radiology photo readings, the radiology specialist did not list the grade, according to Kellgren-Lawrence.

\section{CONCLUSION}

Based on research conducted on respondents diagnosed with genu osteoarthritis at Tarakan Hospital Jakarta in August - October 2019, as many as 40 patients. The results showed $67.5 \%$ of respondents were female, $67.5 \%$ of respondents with $\mathrm{OA}$ genu were $>50$ years old, $67.5 \%$ of respondents with BMI categories $\geq 23,17.5 \%$ OA with KellgrenLawrence grade 1, 22, 5\% OA with Kellgren-Lawrence grade 2, 30\% OA with Kellgren-Lawrence grade 3 and 30\% OA with Kellgren-Lawrence grade 4 . It can be concluded that there is a significant relationship between body mass index and the degree of osteoarthritis genu, so the hypothesis is accepted.

\section{Acknowledgement: None}

\section{Conflict of Interest: None}

\section{Source of Funding: None}

\section{Ethical Approval: Approved}

\section{REFERENCES}

1. Dieppe, P. A., \& Lohmander, L. S. (2005). Pathogenesis and management of pain in osteoarthritis. The Lancet, 365(9463), 965973.

2. Kutlay, Ş., Küçükdeveci, A. A., Elhan, A. H., Öztuna, D., Koç, N., \& Tennant, A. (2011). Validation of the World Health Organization disability assessment schedule II (WHODAS-II) in patients with osteoarthritis. Rheumatology international, 31(3), 339-346.

3. Afolabi, H. A., bin Zakaria, Z., Hashim, M. N. M., Vinayak, C. R., \& Shokri, A. B. A. (2019). Body Mass Index and predisposition of patients to knee osteoarthritis. Obesity Medicine, 16, 100143.

4. Bray, G. A., Kim, K. K., Wilding, J. P. H., \& World Obesity Federation. (2017). Obesity: a chronic relapsing progressive disease process. A position statement of the World Obesity Federation. Obesity reviews, 18(7), 715-723.

5. Hoffstedt, J., Arner, E., Wahrenberg, H., Andersson, D. P., Qvisth, V., Löfgren, P., ... \& Arner, P. (2010). Regional impact of adipose tissue morphology on the metabolic profile in morbid obesity. Diabetologia, 53(12), 2496-2503.

6. Wise, B. L., Niu, J., Yang, M., Lane, N. E., Harvey, W., Felson, D. T., ... \& Multicenter Osteoarthritis (MOST) Group. (2012). Patterns of compartment involvement in tibiofemoral osteoarthritis in men and 
women and in whites and African Americans. Arthritis care \& research, 64(6), 847-852.

7. Cooper, C., Javaid, M. K., \& Arden, N. (2014). Epidemiology of osteoarthritis. In Atlas of osteoarthritis (pp. 21-36). Springer Healthcare, Tarporley.

8. Li, Y., Wei, X., Zhou, J., \& Wei, L. (2013). The age-related changes in cartilage and osteoarthritis. BioMed research international, 2013.

9. Pottie, P., Presle, N., Terlain, B., Netter, P., Mainard, D., \& Berenbaum, F. (2006). Obesity and osteoarthritis: more complex than predicted!.

10. Prieto-Alhambra, D., Judge, A., Javaid, M. K., Cooper, C., Diez-Perez, A., \& Arden, N. K. (2014). Incidence and risk factors for clinically diagnosed knee, hip and hand osteoarthritis: influences of age, gender and osteoarthritis affecting other joints. Annals of the rheumatic diseases, 73(9), 1659-1664.

11. Jiménez, G., Cobo-Molinos, J., Antich, C., \& López-Ruiz, E. (2018). Osteoarthritis: trauma vs disease. Osteochondral Tissue Engineering, 63-83.

12. Wisse, B. E. (2004). The inflammatory syndrome: the role of adipose tissue cytokines in metabolic disorders linked to obesity. Journal of the American society of nephrology, 15(11), 2792-2800.

13. Pye, S. R., Reid, D. M., Lunt, M., Adams, J. E., Silman, A. J., \& O’Neill, T. W. (2007). Lumbar disc degeneration: association between osteophytes, end-plate sclerosis and disc space narrowing. Annals of the rheumatic diseases, 66(3), 330-333.

14. Guehi, C., Badjé, A., Gabillard, D., Ouattara, E., Koulé, S. O., Moh, R., ... \& Danel, C. (2016). High prevalence of being Overweight and Obese HIV-infected persons, before and after 24 months on early ART in the ANRS 12136 Temprano Trial. AIDS research and therapy, 13(1), 112.

15. Schache, A. G., Baker, R., \& Lamoreux, L. W. (2006). Defining the knee joint flexionextension axis for purposes of quantitative gait analysis: an evaluation of methods. Gait \& Posture, 24(1), 100-109.

16. Lehmann, S. V., Andrada, E., Taszus, R., Koch, D., \& Fischer, M. S. (2021). Threedimensional motion of the patella in French bulldogs with and without medial patellar luxation. BMC veterinary research, 17(1), 112.

17. Abumandour, M. M., Bassuoni, N. F., ElGendy, S., Karkoura, A., \& El-Bakary, R. (2020). Cross-anatomical, radiographic and computed tomographic study of the stifle joint of donkeys (Equus africanus asinus). Anatomia, histologia, embryologia, 49(3), 402-416.

18. Chavan, S. K., \& Wabale, R. N. (2016). Reviewing morphology of Quadriceps femoris muscle. Journal of Morphological Sciences, 33(02), 112-117.

19. Cugat, R., Cuscó, X., Seijas, R., Barastegui, D., Álvarez-Díaz, P., Alentorn-Geli, E., ... \& Lama, N. (2018). PRGF on SportsRelated Ligament Injuries. In Platelet Rich Plasma in Orthopaedics and Sports Medicine (pp. 175-189). Springer, Cham.

20. Strobel, M., \& Stedtfeld, H. W. (2012). Diagnostic evaluation of the knee. Springer Science \& Business Media.

21. Falciglia, F., Di Lazzaro, A., \& Guzzanti, V. (2014). The Knee: ligamentous tears. In Pediatric and Adolescent Sports Traumatology (pp. 143-159). Springer, Milano.

22. Henriksen, M., Graven-Nielsen, T., Aaboe, J., Andriacchi, T. P., \& Bliddal, H. (2010). Gait changes in patients with knee osteoarthritis are replicated by experimental knee pain. Arthritis care \& research, 62(4), 501-509.

23. Naibaho, L. (2018). The Description of medical students' interest and achievement on anatomy at faculty of medicine Universitas Kristen Indonesia. International Journal of Sciences: Basic and Applied Research (IJSBAR), 39(1), 121-133.

24. Chen, R., Chen, M., Xiong, J., Chi, Z., Zhou, M., Su, T., ... \& Zhang, B. (2012). Is there difference between the effects of twodose stimulation for knee osteoarthritis in the treatment of heat-sensitive moxibustion? Evidence-Based Complementary and Alternative Medicine, 2012.

25. Reijman, M., Pols, H. A. P., Bergink, A. P., Hazes, J. M. W., Belo, J. N., Lievense, A. M., \& Bierma-Zeinstra, S. M. A. (2007). Body mass index associated with onset and progression of osteoarthritis of the knee but not of the hip: the Rotterdam Study. Annals of the rheumatic diseases, 66(2), 158-162.

26. McQuoid, K. A. (2010). An analysis of changes in hip muscle action of elderly 
women with knee osteoarthritis. University of New Brunswick (Canada).

27. Nadeak, B., Iriani, U. E., Naibaho, L., Sormin, E., \& Juwita, C. P. (2019). Building Employees' Mental Health: The Correlation between Transactional Leadership and Training Program with Employees' Work Motivation at XWJ Factory. Indian Journal of Public Health Research \& Development, 10(6), 1373-1379.

28. SureSh, S., \& Mahendra, J. (2014). Multifactorial relationship of obesity and periodontal disease. Journal of clinical and diagnostic research: JCDR, 8(4), ZE01.

How to cite this article: Yudawijaya A, Utomo TY, Destiana V. Relationship of body mass index to genu osteoarthritis in Orthopedic Polyclinic Tarakan Hospital Jakarta in AugustOctober 2019. Int J Health Sci Res. 2021; 11(5): 410-419. DOI: https://doi.org/10.52403/ijhsr. 20210561 